Submitted: 08.03.2016.

Accepted for publication: 01.12.2016.

\title{
Chaosmic Spasm: Guattari, Stiegler, Berardi, and the Digital Apocalypse
}

\author{
Mark Featherstone ${ }^{1}$ \\ Keele University, Keele, UK
}

\section{doi: 10.5937/comman12-11501}

Abstract: In this paper I explore the intersections of digital media, psychoanalysis, and the subject through reference to Felix Guattari's notion of the chaosmic spasm, which the Italian philosopher Franco Berardi picks up in his work and most recently his book And. Guattari's idea, which appears in his Chaosmosis, designates the fatal acceleration of the media semio-universe towards spasm, or apocalyptic collapse, and the emergence of some new form of schizoid organisation. Following an exploration of Guattari's idea, and a broader discussion of its relationship to his wider thought and Anti-Oedipal collaborations with Deleuze, I consider how Bernard Stiegler may be seen to provide a meta-historical account of Guattari's concept of the spasm in his Technics and Time. According to Stiegler's account, the hyper-acceleration of media forms results in a process of disorientation and de-subjectivization where the individual is destroyed because of their inability to situate themselves in social, symbolic, structures that have collapsed towards hyper-rational, meaningless forms. In Lacanian terms, psychosis becomes a kind of generalised condition. In response to this generalisation of madness, Stiegler imagines the need for a new politics of knowledge and grammar that is able to suture individuals back into wider social systems and provide the kind of secure, careful, space that $D . W$. Winnicott writes about in his work on play. In order to unpack what this politics of culture and knowledge might comprise, I turn to Guattari's work on schizoid subjectivity, or endless subjectivization without subjectivity, and Berardi's contrast between financial semio-capitalism and poetry, in order to suggest an ethical mode of thought and cultural expression that might capture the political core of Stiegler's vision and paint a picture of what human thought might look like on the other side of the new media apocalypse, the chaosmic spasm.

Keywords: chaos, meaning, globalisation, new media, psychoanalysis, subjectivity, apocalypse, Guattari, Stiegler, Berardi

\footnotetext{
1 Contact with author: m.a.featherstone@keele.ac.uk.
} 


\section{What is the Chaosmic Spasm?}

How can the concept of the spasm, which describes muscular over-stretch and a sudden painful compensatory contraction, capture the experience of contemporary new media globalisation? In this article I take the idea of the spasm, and more specifically Felix Guattari's (1995: 135) notion of the chaosmic spasm, to explore the reality of subjectivity in contemporary new media society. The concept of the chaosmic spasm appears at the very end of Guattari's final work, Chaosmosis, which explores the possibility of the translation of the chaos of processes of globalisation into some kind of territorialised fundamental thought able to support a liveable form of subjectivity. Guattari writes:

"Psychoanalysis, institutional analysis, film, literature, poetry, innovative pedagogies, town planning and architecture - all the disciplines will have to combine their creativity to ward off the ordeals of barbarism, the mental implosion and chaosmic spasm looming on the horizon, and transform them into riches and unforeseen pleasures, the promises of which, for all that, are all too tangible." (1995: 135)

In this context the chaosmic spasm describes the transitional moment where nonsensical chaos folds over into meaningful complexity that can be effectively integrated into a new mode of schizoid human subjectivity that is sensitive to endless change and uncertainty. For Guattari (2009), this mode of subjectivity-endlessly-in-the-making, which he calls subjectivization, is the only way to live with the kind of complexity that global capitalism or, in his words, integrated world capitalism has thrown humanity into. However, it is not that Guattari thinks that complexity is problematic or unliveable in itself, because what we find in his Three Ecologies (2014) is a vision of the potential, which is implicit in the recognition and experience of complexity for humans, to truly come to terms with the ecological truth of their existence on earth. The problem of global complexity and the new media universe, which has emerged since Guattari's death in the early 1990s, is, therefore, not simply about complexity in itself, but rather the kind of wide open tech world into which it throws the post-modern subject, a world without effective coordinates or cultural signposts to enable proper, liveable, subject formation. It is this cold, unliveable, technocapitalist world that Guattari wants to over-turn through the chaosmic spasm, which indicates the apocalyptic collapse of human significance in a blizzard of 
empty communication and the possibility of a new way of making meaning that is able to express humanity's place in the world, where the world is built upon an understanding of ecological being on the earth. In order to explore Guattari's (1995: 135) idea of the chaosmic spasm more fully, in the first part of this article I unpack the concept in conversation with Arthur Kroker's (1993) theory of spasm from his book of the same name, before moving on to consider the development of global processes since Guattari's death in the early 1990s. The point of this work is to situate Chaosmosis (1995), which, it seems to me, theorised the potential collapse of integrated world capitalism and the rise of a new symbolic order based on a fully realised recognition of ecological interdependence, in the history of global capitalism and the development of what Hardt and Negri (2000) talk about in terms of empire in the period since the 1990s.

Specifically, here I refer to two events, (1) 9/11 and the subsequent 'war on terror' and (2) the global financial crash and consequent world recession, which might be read through the lens of Guattari's (1995) theory of the chaosmic spasm since what they can be seen to represent is the moment when the overreach of empire became apparent and the spastic phase of globalisation that we currently occupy started to take effect. Apart from social and political manifestations of this spastic phase - which we might understand through reference to the rise of nationalism in America, where Donald Trump has suggested the withdrawal of the land of the free from the world stage, and similar phenomena in Europe, where opposition to the project of European integration has seen the UK vote to leave the EU - we can also trace the impacts of the failure of the global symbolic order that emerged in the late 1980s / early 1990s in the rise of a range of individual psychopathological effects, including depression, despair, anxiety, and outbursts of sadistic violence. We can find examples of these kinds of psychological responses to what we might call global psychosis brought about by the failure of the symbolic system of Guattari's (2009) integrated world capitalism everywhere in contemporary society. Against the depression, despair and anxiety brought about by the apparently meaningless world, many have sought to escape into repetitive addictive behaviours that are able to offer relief from the chaos of life, while others have fallen into suicide or suicidal violence projected onto constructed enemies. Perhaps this is how it is possible to understand the continuum between the savage violence of Islamic State in Syria and Iraq, which is concerned with resistance to the collapse of the Islamic 
psychological world under the pressure of western modernity, and the suicidal violence of European Islamists and so-called lone wolves who take up the cause of Radical Islam in order to rage against their worlds. What the European Islamists in the UK, France and Germany are playing out is their own suicidal response to the collapse of their worlds through the lens of a global and, beyond this, cosmic struggle between good and evil that can give their acts significance. In this respect, it would be correct to say that the European Islamists are mentally ill, since their violence is based upon a paranoid fantasy of escape from the horror of the meaningless present into a meaningful future premised on the destruction of all others, but a mistake to imagine that theirs' is somehow simply an individual pathology that is not founded upon a wider cultural condition of complexity, chaos and the collapse of symbolic integrity (Benslama, 2009).

In order to illustrate this point, and further contextualise Guattari's (1995) theory of complexity and chaos, I also seek to theorise the despair of the present through a discussion of Bernard Stiegler's (2011b, 2012, 2014b) work on disbelief, discredit, default and the failure of the spirit of capitalism. What matters here is that Stiegler locates the disenchantment of capitalism, and the related rise of disbelief and despair that has led to general social collapse, in the emergence of the final phase of late capitalism or what the Italian autonomist followers of Guattari write about through the idea of semio-capitalism (Berardi, 2015; Genosko, 2012; Marazzi, 2008, 2011). According to Guattari (2009: 244), and his Italian followers including Berardi and Marazzi, semiocapitalism refers to the moment when capitalist value escapes materiality and becomes lodged in the pure abstraction of sign. At this point all language becomes subject to the logic of commodification and valuation and there is no meaning beyond the 'more or less' calculations of relative price. In this context, Stiegler $(2011 b, 2012)$ shows that the problem with late capitalism, and in this respect lateness refers to the senility of the economic domination of the world, starts when the symbolic order is reduced to the carrier of quantitative value and no longer enables humans to properly articulate their experiences of the world. When this happens language has no real, qualitative value but simply measures productivity and profitability. This is why the symbolic order fails, and centrally fails as a network able to support civilized subjectivity, with the result that the subject falls into psychosis (recall that in Lacan's work psychosis names what happens when the subject fragments before the failed master signifier and the symbolic order it structures) and a pathological, defensive mode of 
subjectivity defined by aggression towards the external world, which becomes necessarily threatening and destructive. In Stiegler's (2012: 80-103) work the product of this process is the miserable dis-individual, a kind of destroyed self that survives through violent acting out (or what he calls negative sublimation), which becomes the principal means for the assertion of their existence in a world that seems chaotic and meaningless. In order to illustrate this argument, Stiegler (2012: 47) refers to the phenomena of the school shooting, for example Columbine or Sandy Hook, where young men seek to take their revenge on the cold world through the destruction of its future in young people and children. However, we might also refer to the recent terror attacks across Europe, which similarly represent violent expressions of an attempt to make meaning in the world, and other explosions of apparently meaningless violence.

Building upon Stiegler's work, I move on to take up this idea of negative sublimation (2012: 6) and read it against Franco Berardi's theory of the digital apocalypse from his recent book Heroes (2015b), but also And (2015a), After the Future (2011), and Uprising (2012). In Heroes, Berardi supports Stiegler by showing how the collapse of the western cultural symbolic order under the pressure of global capitalism has led to the destruction of individualism and centrally the impossibility of individual action. Here, the collapse of the individual able to make a difference, and the collapse of the hero who acts upon the world, has led to the rise of a culture of violent anti-heroism, symbolised by the violence of figures such as Anders Behring Breivik, who seek to create meaning through notoriety and infamy. In much the same way that Stiegler (2012) attributes the rise of this kind of rage and violence to the collapse of symbolic systems able to ground meaningful subjectivity, in perhaps his most expansive work, And (2015a), Berardi shows how new media globalisation has effectively eroded human forms of communication and destroyed the possibility of the articulation of significance in semio-capitalist representations of value. Under these conditions, Berardi (2015a) explains that there is no hope and no future, since the subject is cast adrift in a sea of meaningless symbols of quantitative value that makes it impossible to imagine the new on the basis of a vision of the present and an understanding of the past. In this respect, Berardi's individual is truly lost in the existential sense of the word because they cannot locate themselves in the world on the basis that they have no real language to articulate their experiences of the present. 
When all that matters is productivity and profitability, experience becomes meaningless. As a result, the future ceases to exist beyond the endless demand to produce more and increase profitability, which is no kind of future at all because it fails to imagine the new. What, then, is the alternative to the dystopia of global capitalism without a future? In the conclusion of my article I pick up Berardi's (2012: 134-171) claim that escape from the horror of the late capitalist nightmare of connectivity, complexity and chaos would have to entail the reclamation of language from the abstraction of finance and new media communication and the reengagement of a poetic approach to expression where language becomes the carrier of embodied experience and perception in the world and perhaps more importantly of being on the earth. In this respect, I think Berardi (2012) can be read with Stiegler (2013: 98), who argues that escape from the destroyed culture of the present resides in a new politics of knowledge, discipline and cultural engagement. However, where I think Berardi (2012: 8) represents an advance on Stiegler is in his reference to the experience of the body. Although he does not fully work out exactly what his embodied critique of semio-capitalist abstraction would mean for the contemporary, my view is that his target is what we might call the semiotic reduction of reality that tears language out of communication with corporeal experience. In the semio-capitalist world of Berardi (2012), and for that matter Stiegler (2014a), the problem is that language has become subject to the logic of floatation and has no relation to real experience. This is, therefore, why Berardi's (2012: 20) notion of the uprising is not simply about a taste for poetry, but rather concerns the creation of new worlds founded in the articulation of experience and perception, and Stiegler's (2013) critique would benefit from the language of embodiment to gloss his theory of cultural politics. In this instance, it is not simply that the escape from the horrors of the permanent ruined present of late capitalism relies on a kind of elite cultural politics, where there is more to life than work and money, but rather that these cultural politics must reimagine the world through the expression of lived experience on the earth. In this way, the world, or the construction of a symbolic order able to sustain subjectivity, emerges from and presupposes expressions of an embodied experience and perception of earth.

Finally, I conclude my article by returning to Guattari's (1995: 135) theory of the chaosmic spasm, which I seek to contextualise in terms of the theory of geo-philosophy, that he wrote about in his final work with Deleuze, What 
is Philosophy? (1994). The point here is to show that what Guattari imagines through the figure of the chaosmic spasm is a new ecological, terrestrial mode of subjectivity rooted in the experience and perception of earth. Since ecology is characterised by complexity, this new form of subjectivity could never form around a static paranoid fantasy of self-identity, but would instead escape the desperate need to assert defensive security through its ability to express experiences and perceptions of an earth-bound existence in a new world that is sensitive to what it feels like to live, suffer and imagine other ways of life. In this way I show how this new reality, the reality of the subject endlessly made and remade in the experience, perception and expression of life on earth and in the world, is what Guattari (1995) imagines when he writes of chaosmosis. It is this form of identification, which would render complexity liveable, that Guattari (2009) thinks will emerge from the catastrophe of integrated world capitalism, and which both Stiegler (2009) and Berardi (2015a) explore in their own works that are concerned with what we might call the contemporary new media apocalypse. However, before I reach the point where I conclude in a discussion of the ecosophical mode of subjectivity, I want to take up a discussion of the concept of the spasm and the ways it is understood by first, the Canadian media theorist Arthur Kroker (1993) and second, Guattari (1995), who complicates the idea through reference to the concept of the chaosmic spasm.

\section{The Chaosmic Semio-Capitalist Spasm}

In his Spasm (1993) the Canadian media theorist Arthur Krorker explores the other side of the virtual, new media utopia that emerged in the 1990s. Written in the teeth of this utopia, where the limitations of reality itself seemed to have collapsed before the virtual where everything seemed possible, Kroker suggests that the problem of the new computational universe is that the possibilities that it might allow are firmly held in check by a technological concern for functionality. Even though it may not have been immediately apparent, the new utopia was never, in Kroker's view, open to human possibility. Instead, it was primarily concerned with the absolute expansion of a logical system organised around digital data, and the representation and reconfiguration of the world in instrumental terms. In this way, Kroker reverses Deleuze and Guattari's (1987) idea of the body without organs, which was primarily about the schizophrenic overcoming of the bounded organism in the terrestrial body 
ecological, through the idea of the organs without a body (1993: 36-46), where all that matters is functionality and the kind of rationality that ends in the nihilistic disenchantment of wider significance. The difference between these two figures is, therefore, that while Deleuze and Guattari's (1987) formulation seeks to found subjectivity in significance based upon the ecology of life, Kroker's (2003) virtual utopia attempts to escape the limits of terrestrial reality for computational metaphysics and the flesh of earth-bound identity for the new infinite space of the digital where life can be made and remade without concern for boundaries. However, the problem with this new utopianism, which we might call the final modern utopia based upon the strategy of escape, is that its reliance on what Kroker (1993: 5-6) writes of in terms of a logic of floatation was actually tightly bound in terms of its fanatical adherence to the instrumental rationality of digital universe. Here, everything can be reduced to the representation of zeroes and ones. Although the virtual utopians often imagined the infinite possibilities for novel experience that might be opened up by the new computational reality of the internet, Kroker (1993: 7) writes of the great 'recline of western civilization' in order to illustrate the death of real experience in easy, coded representations of reality. The truth of the new virtual utopia of the 1990s was, thus, in Kroker's view a kind of laid back, exhausted stroll towards the end of humanity. Slouching towards the apocalypse, Kroker's (1993) vision of the experience of spasm emerges in the abyss between digital ecstasy, where everything seems possible on condition of its functionality, and earth-bound decay, brought about by the abandonment of experience and perception in a utopian fantasy of the absolute reach of numbers and digital data.

In Kroker's (1993: 39) theory of the new world algorithm, where numbers and data are the ontological truth of the reality of experience and perception, he shows how purity becomes the central political category and mutations of newness and unpredictability are destroyed in the name of functionality. The irony of the virtual utopia was, in this respect, that it produced a kind of nightmarish computational dystopia, what Kroker (1993: 160) calls a zero-culture, characterised by a form of cyber-puritanism allergic to the thickness of the flesh, experience, perception, and more broadly terrestrial life itself. It is this situation, where the virtual sphere of computation expands to the detriment of embodied existence, which returns in the form of a kind of excremental remainder, that Kroker captures in the concept of spasm. It is the same experience of spasm 
that I think Guattari writes of in the final pages of his book Chaosmosis (1995: 135), where he opposes the hyper-rationalism of what he calls integrated world capitalism to the reality of earth-bound existence and shows how the distance between these two worlds finds its limit in the chaosmic spasm or momentary phase transition, which sees one universe of (in)significance collapse before some other vision of the world.

The problem of integrated world capitalism or semio-capitalism is, in the work of the key thinker of the autonomists Christian Marazzi (2008, 2011), that economic value is no longer related to things. Reading Marazzi's (2008: 13-69) work we can see that upon the deregulation or floatation of money by Richard Nixon in the 1970s, there was no longer a solid relationship between money and materiality (precious metals), which meant that money was able to take flight from the world. But if the issue was the simple separation of value and things, the problem might be one more concerned with the integrity of money, rather than some wider crisis of meaningfulness itself, which might have opened up utopian possibilities for the rearticulation of value. However, what floatation, and the emergence of semio-capitalism, actually produced was the colonisation of reality by the symbolic form of money that was able to transform its idealistic redundancy into a virtue on the basis of its absolute commensurability. Herein resides the real catastrophe of semio-capitalism, integrated world capitalism, and symbolic value for Guattari and later his autonomist followers. It is not simply that money floats off into the metaphysical universe of Platonic forms, but rather that it comes back in its redundancy to over-code human and non-human reality and transform everything into an empty semblance of economic value. The ultimate Platonic sleight of hand is, therefore, the semio-capitalist reduction of terrestrial life to abstract value that becomes (virtual) reality itself, which is then absolutely malleable precisely because it is no longer real in the thick phenomenological sense of the term we might find in the work of Merleau-Ponty (2012).

It is this situation that Guattari $(1995,2014)$ thinks has become unsustainable and unliveable for humans because they are essentially bound to the flesh of the earth through their own bodies, which they cannot escape. Apart from the violation of the thickness of things in the name of the infinity of abstraction, the catastrophe of semio-capitalism is that it destroys the fleshy integrity of the symbolic order, which holds the subject in place through the provision 
of a meaningful world, through its totalitarian reduction of communication to rational calculation concerned with productivity and profitability. Thus the two-fold problem of the dystopic system that Guattari (2009) writes about in terms of integrated world capitalism is that it transforms the human life world into a paper thin construct organised around empty capitalist objectives focused on profitability and at the same time blocks the emergence of alternatives to this meaningless universe through the transformation of economy into a system defined by scarcity and the struggle for survival. Cast out of the systems of significance that might enable social action, the individual collapses towards the figure that Stiegler (2012: 80-103) talks about through the idea of the dis-individual, and humanity starts to resemble the form of animality that Heidegger (2001) found poor in the world. In fact, the situation may be even worse than this, since there is a distinct difference between the animal and the dis-individual, which is that the animal occupies an ecological umwelt that organises its behaviour, whereas the dis-individual is thrown out of the meaningful world into a kind of barren un-world that seems ecologically unsustainable and unliveable. This is how, I think, integrated world capitalism penetrates through to the level of subjectivity and essentially turns humans into zombies, staggering through their environment in a liminal state somewhere between life and death.

The zombification of the modern or post-modern subject has been brought about by the reduction of the symbolic order to the level of a kind of instrumental command system that leads to the emergence of a hyper-rational subject that cannot easily survive and is now on the verge of total collapse. In this respect, the problem that the desperate dis-individual, or we might say post-mortem subject, faces, is that the contemporary situation is worse than that which Nietzsche (1961) imagined in the 19th century when he wrote of the horror of Godless modernity, simply because the abyss of capitalism blocks the possibility of the Übermensch through its transformation of reality into code. Here, the situation of integrated world capitalism more closely resembles the horror-show imagined by Weber (2001: 123) in the final pages of his work on the spirit of capitalism, where the iron cage transforms society into a system of bureaucratic rules and regulation devoid of wider significance, because the existential abyss is always-already full of nonsense and there appears little room for the new. However, I think that it is this condition that Guattari (1995: 135) considers 
representative of a kind of transitional moment, where apocalyptic collapse opens out onto the possibility of something else. This is what, in my view, he captures in the idea of the chaosmic spasm, precisely because the present seems entirely unliveable and unsustainable. Under these post-human conditions, the chaos of global complexity - which seems meaningless because of high levels of post-human technological development, the lightning fast speeds of economic interaction, and levels of inter-connectedness that mean that events seem to appear ex nihilo - suggests the possibility of utopian innovation in the creation of what Guattari (1995: 10-11) calls a novel ethico-aesthetic paradigm. But how would this new paradigm work?

Although Guattari is light on the precise detail of the possible emergence of this new order, my view would be that it would occur through a necessary phase transition from integrated world capitalism to a new ecological vision of the reality of the world. Thrown out of the human world of significance into the posthuman quantitative un-world of balance sheets, the monstrous, de-subjectified, dis-individual would need to return to the earth and to their experience and perception of suffering in order to imagine a new world beyond the present. Given the poverty of language available to the autistic un-self, they would need to fall back on the most basic terms concerned with the expression of pain and suffering in order to articulate their ethical opposition to the semio-capitalist un-world and from there seek to represent the truth of schizophrenic subjectivity where the self only ever survives through its relation to others and its terrestrial life support machine. This is, in my view, the kind of world that Guattari (1995: 108) imagines and what he means when he writes of machinism in his ecosophical works. In this context, machinism does not refer to the Heideggerian nightmare of modernity from his The Question concerning Technology (1977), where everything collapses before the instrumental rationality of the machine organised around the world picture that enframes existence itself, but rather the more ancient conception of technology captured in the term techne, which suggests the sympathetic communication and coevolution of humanity and environment that we also find in the work of Gilbert Simondon (2016). Against this more ancient conception of technological machinism, which suggests ecological communication and interaction, it is, I think, possible to argue that the virtual utopia that Kroker writes of in his Spasm (1993) represents the final stage in the development of Heidegger's modern technological system 
precisely because of the ways in which it uses, abuses and brutalises man and nature in the creation of a totally integrated system organised around infinite commensurability and endless exchange in the name of profitability.

While this model of technology is programmatic and static in terms of its conception of change, what Guattari (1995: 108) imagines through the term 'machinism' is open, dynamic and defined by deterritorialisation. However, the converse is also the case. Where the modern, and what would later become the post-modern, version of technology seeks to escape all limits in the name of abstraction and virtuality, Guattari's ecosophical notion of machinism communicates with other machines in the name of the creation of bounded sense and significance in the otherwise chaotic un-world. In this respect, I think Guattari's understanding of technology respects the limits of terrestrial space, which is precisely what we find expressed in his theory of geophilosophy outlined in his final book with Deleuze, What is Philosophy? (1994), even though this humility before ground is endlessly extended by the shifting nature of reality (the chaotic un-ground) to produce a dynamic, fundamental thought in touch with the abyss of experience, perception and earth. This is what Guattari (1995: $80-87$; 112) means by chaosmosis - which refers to the way that chaos can find a temporary form in a kind of fundamental thought that is simultaneously able to make sense and respect the endless turbulence of reality - that he attempts to explain through a rearticulation of Freud's (2003) theory of the death drive from his key paper Beyond the Pleasure Principle. Where Freud takes his young relative's game of fort / da for a symbol of the basic inertia of being that is endlessly repetitive of cycles of birth, life, and death, Guattari (1995: 72-76) points out that the first stage of the game (fort) may be taken to represent the traumatic experience of chaos that the little boy orders through the second stage of his play (da) in the name of the creation of sense in the world. While Freud emphasises the essential trauma of being, which humans can never escape until they flatline out of existence, Guattari's more optimistic reading of the work of life concerns the way that humans are able to make meaning in the world in order to organise their experiences.

It is possible to argue that Guattari (1995: 135) saw the potential collapse of integrated world capitalism in the happy days of the late 1980s and early 1990s, when the really existing communism fell before a capitalist future that seemed to promise endless freedom and prosperity to those who had been locked out 
of the American-led boom since the 1950s. When Frances Fukuyama (1992) wrote of the end of history in the triumph of capitalism and George Bush I spoke of the NWO (New World Order) of American power, Guattari's early 1990s critique of complexity seemed off the mark, simply because there was a clear organising structure through which to understand the new globalised world, which was defined by concepts such as freedom, democracy and prosperity. In many respects the virtual utopia of the 1990s, which saw the internet become perhaps the most visible representation of processes of globalisation, seemed to make these abstract principles virtually concrete, since it appeared to enable endless freedom to communicate, consume and develop. The emergence of Web 2.0 and social media further supported the fantasy of the virtual utopia through the promise of a new kind of cyber-democracy and cyber-society and in many respects it seemed that Marshall McLuhan's (2001) media utopia of the 1950s had been realised at the end of the 20th century. However, in much the same way that McLuhan's (2001: 45-53) utopian story of global media was qualified by his dark vision of the gadget lover, who makes up for their loss of embodiment through the possession of the high tech fetish object, it soon became clear that the virtual utopia was also a new disciplinary or, to refer to Deleuze's (1997: 177-183) famous essay, control space for the integration of workers, who would now never stop working, and consumers, who were similarly never out of reach for corporations desperate to increase their profit margins.

In this way, the virtual space of absolute freedom, the abyss of possibility founded upon the bright light of the screen, opened out onto a nightmarish dystopia, a slack jawed world defined by trans-fixed cybernauts caught somewhere or nowhere between here, there and everywhere. Caught up in the virtual un-world, where one could apparently float free of the ground of terrestrial existence, even the promise of 'the social network' where one could make millions of new friends, seemed to fail before the logic of commodification and quantification, which saw friends become immaterial objects that one collects in the name of the quantifiable popularity necessary to offset the void of real life beyond the shiny, happy world of screen culture. In this respect it is possible to read what we might call the spasm of new media culture, which saw the virtual utopia contract from its expansive utopian phase of absolute possibility back towards a more dystopian realisation of the limitations of the immaterial 
computational world, in terms representative of the evolution of the wider culture of floatation from the 1990s through to the present period where there seems to be no way to move forward, but through a return to the real world of terrestrial bodies. The signs of this impasse have become clear since the turn of the 21 st century. According to Slavoj Žižek's (2009) exploration of the failure of the final utopia of the 20th century in his book First As Tragedy, Then As Farce, the first shock to the New World Order was 9/11, which struck at the very heart of American economic power, and opened out onto the 'war on terror'. Akin to Vietnam, which similarly proved that technological power can never overcome territorial resistance, the 'war on terror' was soon revealed to be unwinnable, economically unsustainable, and perhaps even worse, enormously destructive for the project of global integration, which began to freeze before the translation of communication into its fearful other, contagion. On the back of the shock of $9 / 11$, the second shock to the virtual utopia took the form of the global financial crash of 2008, which further undermined the semio-capitalist project by showing that the creation of money from money ex nihilo was ultimately an unsustainable project: the repressed real would continue to return from the abyss of materiality hidden from view by the shiny world of virtuality.

The deep economic problem that the crash revealed was essentially concerned with Nixon's floatation of money in the early 1970s; the subsequent deregulation of finance and the rise of fractional reserve banking; and the overleveraging of available assets in the form of debts that turned out to be unsustainable because of a lack of real economic activity. Of course, this process of financialisation, which took place from the 1970s through the 1980s and 1990s up to the crash in 2008 under the banner of neoliberal economics, was the motor of globalisation and what Guattari (2009) wrote about in terms of integrated world capitalism. When capitalism started to fail in the 1970s, because of a crisis of productivity and a related lack of growth, floatation and financial innovation seemed to represent the way forward, because they allowed for the expansion of capitalism beyond the limits made possible by real production alone. While this process organised around the virtual creation of money from money for investment in innovation and financial profit was supposed to be made safe by systems of securitisation, these structures could not prevent the near collapse of the system in 2008 because of the abyss that had opened up between levels of debt based in virtual money and the really existing value founded in the econ- 
omy of bodies and things. At this point, the virtual utopia of free floating signs came crashing back down to earth in the revelation of its economic limits in reality. However, while the supporters of neoliberal financialisation have sought to save the system, from the point of view that the problem of 2008 was an issue of greedy bankers looking to make a killing from people who would never be able to make their repayments, what Guattari's work and particularly his Three Ecologies (2014: 27-28) suggests is that the financial crash was less representative of a narrow issue of economic mismanagement and more concerned with global ecological sustainability relating to first, the ability of humans to live in a complex world where qualitative significance has been undermined by quantitative calculation; second, the possibility of society and social integration in a world where people have lost touch with embodied language and the primary good has become competition; and finally, the potential of the world to survive the progressive destruction of the earth that sustains organic life by capitalism, which, even in its virtual form where it seeks the elimination of materiality, lives off the exploitation of planetary resources.

From the point of view of Guattari's $(1995,2014)$ ecosophical works, the problem of integrated world capitalism and the virtual utopia is, therefore, far more expansive than an issue of financial mismanagement and instead relates back to the post-modern rejection of materiality in the name of the apparent freedom of abstraction that has now run into its outer limits in the formation of a bleak un-world that suffers the loss of its terrestrial body. In this sense, it is possible to argue that the problem with the present is actually less about the psychotic flight from reality into fantasy (the post-modern critique of the hyper-real we find in Baudrillard (2010), for example) and more about a schizoid break from the fantasy of virtual semio-capitalism that has occupied people since the 1970s but has now run its course in the contemporary period, which we might talk about in terms of post-mortemism defined by the chaosmic spasm, the terror of endings, and existential questions about what comes next. For Guattari and his autonomist followers, such as the contemporary German thinker Gerald Raunig (2016), the answer to this question is, I think, that we must seek to translate the lack of a post-modern virtual future, which finds representation in the post-mortemism of the destroyed individual, into a potential excess, which opens the otherwise closed, militarised self out onto others and the earth itself in the form of the figure that Raunig calls the dividual. Where 
Stiegler's (2012) dis-individual represents the person who has lost their sense of self founded in the ruined symbolic order and cannot think beyond the meaningless present into the future for this reason, I think that the potential of the dividual resides in the possibility of the conversion of ruined subjectivity that knows nothing but pain and suffering into an ecological being founded upon their ability to communicate their experience and perception to others on the basis of their common occupation of earth-bound bodies. This is, in my view, how the ecosophical response to spasm, which represents the painful, strained relation between the virtual and the material might begin to find resolution in the foundation of a new sustainable world based upon being on the earth. In the final section of this article I propose to outline the longer history of the spasm through reference to Stiegler $(1998,2009)$ and Berardi $(2012,2015)$ before returning to Guattari (1995) to argue that the other side of the chaosmic spasm must involve a return to the kind of ecological being he wrote about with Deleuze in his theory of geo-philosophy (1994).

\section{The Politics of Spasm}

Although he never mentions the idea of spasm, it is possible to argue that Bernard Stiegler (1998, 2009, 2011a) provides a pre-history of the concept in his three volume work, Technics and Time, through his discussion of what he calls disorientation. In the first volume of this study, The Fault of Epimetheus (1998), Stiegler picks up Plato's (2009) Protagoras, and specifically the myth of Epimetheus (16-18), to oppose the Promethean reading of technology where the machine represents a symbol of human superiority over the world. In order to oppose this story, Stiegler refers to Prometheus' brother, the comic figure of Epimetheus, who forgets to make sure that humans are ready for entry into the world. The fault of Epimetheus is that he provides every other animal with the means of survival (claws, wings, sharp teeth, thick fur and so on), but forgets about men, which means that Prometheus has to steal fire from the Gods in order to give humanity a fighting chance in the state of nature. We know the rest of the story, which concerns the punishment of Prometheus and the emergence of techno-man, but the importance of the reference to Epimetheus for Stiegler is less clear. It turns out that the importance of Epimetheus is that he illustrates humanity's prematurity. We are always born too soon, inadequate, in a state of default, and have to spend the rest of our lives (history) trying to make up for 
this lack through technological development. At this point we enter familiar Heideggerian (2001) territory, where we learn that the difference between animals and humans is that animals live in ecological harmony with nature while humans have an uncanny world-forming relation to their environment, even though Stiegler's (1998) point is always to emphasise human lack. The rest of Stiegler's history, which develops through volume II of Technics and Time (2009), revolves around what happens when technological evolution starts to outpace humanity. When this happens the very mechanical organs meant to support human life turn upon their creators and become monstrous things that throw their former masters back into a state of inadequacy. In order to capture this problem, which refers back to Heidegger's (1977) critique of modern technology, but also Marx's (1998) work on estrangement and proletarianisation, Stiegler (2009) explains that humans enter into a state of disorientation, since they live in a high tech world beyond their comprehension. In other works, including his book on youth and the generations (2010), Stiegler points out that the neoliberal economy and the exploitation of communication in the name of profitability exacerbate the problem of disorientation because the use of media to capture consumers means that language is no longer available for mapping the world and making sense. It is through this idea, which Stiegler (2014a) talks about in terms of symbolic misery, that I think it is possible to connect his work to the theories of the contemporary critics of semio-capitalism, such as Marazzi $(2008,2011)$, who show how the potential of language to transmit human significance breaks down before its neoliberal transformation into a means to promote capitalism. When language no longer works to enable the translation of real experience and perception into words suitable for communication with others in the name of the creation of the world, humans effectively fall out of the symbolic order and collapse back into a kind of psychotic state of nature. Thus we encounter the experience that Guattari (1995: 135) writes of through the idea of the chaosmic spasm.

Cast out of symbolic structures into near chaos, men become bankrupt, in default, caught in a state of existential lack, and thrown back upon their animality. This is the case even though we have seen that this connection of the dis-individual and animality might be overly optimistic, since the animal lives in harmony with the world, while the dis-individual occupies an uncanny, monstrous un-world. However, it is precisely here, in the teeth of chaos, that 
the possibility of the new emerges, because the destruction of the technohuman and the birth of a new kind of post-mortem savage opens up the space for a reconnection to experience and the expression of the perception of what it is to occupy the position of earth-bound life. But Stiegler (2012: 4) is clear that this will not be a painless process, since the contemporary moment has become about the desperate attempt to hold on to the ruins of modern and post-modern symbolic systems through addictogenic forms of identification characterised by the primacy of drive over desire. For Stiegler $(2010,2012)$, this situation comes about because late capitalism exploits the destruction of desire, which necessarily relies on the integrity of human symbolic systems to create meaningful objects, in the emergence of drive-based economics where the addictogenic nature of drive makes it possible to sell everything and anything on the basis that 'this thing' will fill the dark abyss at the centre of 'your' life. Following Adorno and Horkheimer (1997), however, Stiegler is clear that drive is a fatal (or indeed thanatological) machine, since its objective is the reduction of the misery, pain and horror of the traumatic life lived in the un-world where there is no safety, security, or sense of home in others or in the wider environment, but what it actually achieves is the augmentation of alienation, estrangement and objectification. Against drive, which simply piles misery upon misery, Stiegler (2013: 132-133) states that educators must seek to engage in a battle for the integrity of knowledge, thought and significance, but what he fails to explain is that these new cultural politics must prioritise the relationship between language and other forms of expression and human experience, perception, and being on the earth, because it is precisely this which has been lost in the horror story of neoliberalism.

Following this train of thought, perhaps it is possible to put Stiegler's (2013: 1-4) reference to Winnicott's (2005) theory of play, where the toy becomes a symbol of security and safety and a container for meaningful interaction, in conversation with Guattari's (1995) own extensive discussion of the object, which turns the oedipal triangle of Daddy, Mummy, and Me into an ecological dialogue between Self, Other, and the ultimate object, Earth in order to properly ground his account in a theory of earth-bound life. Moreover, my sense is that this eco-phenomenological critique of the contemporary is also the hidden basis of Berardi's $(2012,2015)$ recent works, including And, which is subtitled The Phenomenology of the End. In terms of explaining the problem of the end, 
Berardi follows Stiegler in respect of his view that the end concerns the inability of humans to effectively articulate a vision of the future that is qualitatively different from the present. However, where Berardi (2015a: 9-111) departs from Stiegler is in the way he locates this problem in the politics of the global network, which he explains through the opposition between conjunction, where self and other meet in such a way that changes both sides of the interaction, and connection, which he thinks dominates today, and comprises a programmatic model of debased sociality where there is no deep engagement or transformative effect upon either person. For Berardi, conjunction represents true human relationality, where individuals engage with each other empathetically on the basis of their common occupation of a world and, beyond this, the earth itself. By contrast, he writes of connection in terms of the simulation of interaction, where engagement takes place through the medium of a technological network that sets rules and regulations about how relationality should take place. In other words, the interaction is already mapped out and planned, and its future outcome is always already known. Berardi (2015a: 233-331) points out that this leads to, on the one hand, the autistic disassociation of self from others and nature, and, on the other hand, the emergence of a kind of totalitarian or globalitarian network where everybody seems to be friends with everybody else, on the basis that the programmatic logic of commensurability ensures that nobody would have a reason to not be friends with anybody else.

But the key point here is that this global negative friendship network (think Facebook or Twitter) is a simulation that masks the reality of the monstrous machine that alienates people from their ecological being in order to transform them into tech-no-subjects who follow its programmatic logic on the basis of their melancholic despair about their lost object of love - the other, the world, the earth itself. This is, essentially, Berardi's (2015a) critique of new media, which is that the network has become a machine for the provision of the simulation of intimacy in a cold world where true intimacy has been banned by a global, technological system that is allergic to the thickness of materiality that necessarily refuses its own reduction to objective truth or quantifiable value. Living in the cold technological un-world, it is no surprise that people cling to their gadgets, which connect them to the global network that can provide a virtual sense of home, and seek to lose themselves in connectivity and fantastical cyber-space. The contemporary new media network has become a technological 
surrogate, which was, for Avital Ronell (1989: 280), exactly what Alexander Graham Bell unconsciously understood when he called America's first telephone network, $\mathrm{Ma} \mathrm{Bell}$, in 1876. Thus, the new media network stands in for mother, and provides the simulation of safety and security that human subjects would have otherwise found in their real mothers, before the screen found its way into every space in the home. However, the problem with this 'new media Mom' is that she is jealous and possessive. She seeks to capture and control her children in ways that even Freud's (2003) original nightmarish engulfing mother who comes to symbolise death never would. This is the case because she knows she needs to keep them away from their real Moms, and beyond them, their common global mother, mother earth. This is why techno-Mom traps her children within cyber-space and what Berardi (2015a: 41-48) calls cyber-time, which requires the tech-no-subject to spend their life online in order to keep up with the blizzard of communication flowing across the network and through their inbox. For Berardi (2015a), this is the final form of futurism, the futurism of the end times, because there is now no more space and no more time for expansion to happen. Where space is concerned, processes of globalisation meant that the earth became lost somewhere deep underneath the un-world of late capitalism, where all that matters is work and shopping, but this soon opened up onto the final frontier of time and the colonisation of every moment by economic logic. Here, the difference between work and free time fell into what we might call capital time, where every living moment becomes about value creation, and beyond this the automisation of humanity, which comprises the destruction of freedom in the necessity to work and consume. For Berardi (2015a: 41-57), it is this situation that has led to the rebellion of the embodied mind in the endless list of mental health conditions that plague the contemporary individual - anxiety, depression, dysmorphia, addiction, and so on - which are, in short, psychological representations of spasm.

Finally, the condition of spasm, which is the focus of this article, has its own kind of politics, which are concerned with the desperate attempt to escape from the pain of estrangement. While many have sought to escape into pharmaceuticals in order to speed up, slow down, get hard, or whatever other response is necessary in order to survive the un-world, others have fallen into alternative kinds of addictive behaviour. Regarding sex addiction, for example, Berardi (2015a: 50) notes that the lonely cybernaut replaces real intimacy with the 
simulation of sexual interaction in the consumption of hard-core Californian porn straight out of the San Fernando Valley, where pumped up sexual superheroes fuck like machines in the name of a barren kind of pleasure that knows no other. Ironically, Berardi (2015a: 68-91) thinks that it is possible to trace the hyper-sexualisation of contemporary culture, which objectifies the other in porno scenes that strip back its phenomenological depths until there is nothing left but a stupid lump of flesh, to the original American puritans because they were the first settlers who turned against the organic world, the body and the flesh because of its imperfections and relationship to sin. In a sense, this explains the strange ambivalence of the online porn scene, which resides in its simultaneous fascination and revulsion with the flesh, and the reason why the sexualisation of tech-no-society seems to know no bounds. While techno-capitalism pushes ever further into abstraction, the destroyed subject seeks out estranged representations of their former fleshy self only to lose this immediately in cold mechanical fucking on screen that transforms the pornstar into a mindless thing, closer to Heidegger's (2001) rock, which seems absolutely un-related, than the animal poor in the world. The result of this immediate cancellation of the pleasure that comes from intimacy in the horror of objectification on screen is that the lost subject experiences the compulsion to push on ever further into pornographic culture, concerned with the disappearance of phenomenological depth in the transformation of bodies into data.

But what is the objective here? Surely the objective of the online porn addict is the identification of what it feels like to have a body, to experience intimacy with the other, and relate to them on the basis of a common experience of the earth, without the engagement of bodies that are impure in the technoscientific semio-capitalist universe of abstract signs and symbols. Since this is a fatal strategy, and there is no way to experience intimacy without some level of carnal interaction, the estranged figures, which Berardi (2015a: 96-110) calls neo-humans fall into addiction and, in the infamous case of the Japanese Hikikomori, or 'shut in', retreat back into media technology in a desperate attempt to reach out to the world of others. But if this represents one side of the politics of spasm, which Berardi (2015a: 311-321) thinks will eventually result in the emergence of a new form of neo-human readjustment, what he calls neuro-totalitarianism, where the embodied self is totally aligned with the global circuitry of semio-capitalism through the mapping and manipulation of neural 
networks, the other side of the strained, stressed relation between technology and humanity resides in Stiegler's (2013) cultural politics, Berardi's (2012) poetic uprising, and ultimately Guattari's (1995) chaosmic creation of ecological sense - the ethico-aesthetic paradigm. Where Stiegler pushes for a form of culture that might make life meaningful, and Berardi suggests the reclamation of language from semio-capitalism in the name of a return to a poetic form of language that is able to express human experience and perception in the world, Guattari's ecosophy shows how the escape from the contemporary impasse will not come through ever more virtuality, but instead requires a new eco-politics that recognises the organic limits of the individual, the position of the individual within a society made up of others, and the dependence of this social world of significance upon the earth, which ultimately supports life and cannot be simply expended in the name of profitability. Thus, I think that it is possible to read Guattari, Stiegler and Berardi together and ultimately understand their critiques of spasm culture through reference to Guattari's final work with Deleuze, What is Philosophy? (1994), where geo-philosophy becomes a vehicle for thinking through a new ecological utopianism: a minor utopianism characterised by humility rather than hubris, and a deep understanding of the ontological truth of what we might call being on earth. The minor utopia is, therefore, the hopeless hope found on the other side of the chaosmic spasm, which signals the collapse of civilization into neoliberal barbarism, and the radical potential that Guattari, Stiegler and Berardi similarly search for in the new media apocalypse. 


\section{References}

Adorno, T. \& Horkheimer, M. (1997). Dialectic of Enlightenment. London: Verso.

Baudrillard, J. (2010). America. London: Verso.

Benslama, F. (2009). Psychoanalysis and the Challenge of Islam. Minneapolis: University of Minnesota Press.

Berardi, F. (2011). After the Future. Oakland, CA: AK Press.

Berardi, F. (2012). Uprising: On Poetry and Finance. New York: Semiotext(e).

Berardi, F. (2015a). And: Phenomenology of the End. New York: Semiotext(e).

Berardi, F. (2015b). Heroes: Mass Murder and Suicide. London: Verso.

Deleuze, G. (1997). Negotiations: 1972-1990. New York: Columbia University Press.

Deleuze, G. \& Guattari, F. (1987). A Thousand Plateaus: Capitalism and Schizophrenia. Minneapolis: University of Minnesota Press.

Deleuze, G. \& Guattari, F. (1994). What is Philosophy? London: Verso.

Freud, S. (2003). Beyond the Pleasure Principle and Other Writings. London: Penguin.

Fukuyama, F. (1992). The End of History and the Last Man. New York: Basic Books.

Genosko, G. (Ed.) (2012). Felix Guattari in the Age of Semiocapitalism. Edinburgh: Edinburgh University Press.

Guattari, F. (1995). Chaosmosis: An Ethico-Aesthetic Paradigm. Sydney: Power Press.

Guattari, F. (2014). The Three Ecologies. London: Bloomsbury.

Guattari, F. (2009). Soft Subversions: Texts and Interviews: 1977-1985. Cambridge, Mass: MIT Press.

Hardt, M. \& Negri, A. (2000). Empire. Cambridge, Mass: Harvard University Press. 
Heidegger, M. (1977). The Question Concerning Technology and Other Essays. New York: Harper.

Heidegger, M. (2001). The Fundamental Concepts of Metaphysics: World, Finitude, and Solitude. Bloomington, IN: Indiana University Press.

Kroker, A. (1993). Spasm: Virtual Reality, Android Music, and Electric Flesh. New York: St Martin's Press.

Marazzi, C. (2008). Capital and Language: From the New Economy to the War Economy. New York: Semiotext(e).

Marazzi, C. (2011). Capital and Affects: The Politics of the Language Economy. New York: Semiotext(e).

Marx, K. (1998). The Economic and Philosophic Manuscripts of 1844 and The Communist Manifesto. New York: Prometheus Books.

McLuhan, M. (2001). Understanding Media. London: Routledge.

Merleau-Ponty, M. (2012). Phenomenology of Perception. London: Routledge.

Nietzsche, F. (1961). Thus Spoke Zarathustra: A Book for Everyone and No One. New York: Penguin.

Plato (2009). Protagoras. Oxford: Oxford University Press.

Raunig, G. (2016). Dividuum: Machinic Capitalism and Molecular Revolution. New York: Semiotext(e).

Ronell, A. (1989). The Telephone Book: Technology - Schizophrenia - Electric Speech. Lincoln, NE: University of Nebraska Press.

Simondon, G. (2016). On the Mode of Existence of Technical Objects. Minneapolis: Univocal.

Stiegler, B. (1998). Technics and Time: Volume I: The Fault of Epimetheus. Redwood, CA: Stanford University Press.

Stiegler, B. (2009). Technics and Time: Volume II: Disorientation. Redwood, CA: Stanford University Press.

Stiegler, B. (2010). Taking Care of Youth and the Generations. Redwood, CA: Stanford University Press.

Stiegler, B. (2011a). Technics and Time: Volume III: Cinematic Time and the Question of Malaise. Redwood, CA: Stanford University Press. 
Stiegler, B. (2011b). The Decadence of Industrial Democracies: Volume I: Disbelief and Discredit. Cambridge: Polity Press.

Stiegler, B. (2012). Uncontrollable Societies of Disaffected Individuals: Volume II: Disbelief and Discredit. Cambridge: Polity Press.

Stiegler, B. (2013). What Makes Life worth Living: On Pharmacology. Cambridge: Polity Press.

Stiegler, B. (2014a). Symbolic Misery: Volume I: The Hyperindustrial Epoch. Cambridge: Polity Press.

Stiegler, B. (2014b). The Lost Spirit of Capitalism: Volume III: Disbelief and Discredit. Cambridge: Polity Press.

Weber, M. (2001). The Protestant Ethic and the Spirit of Capitalism. London: Routledge.

Winnicott, D. W. (2005). Playing and Reality. London: Routledge.

Žižek, S. (2009). First as Tragedy, Then As Farce. London: Verso. 
Chaosmic Spasm: Guattari, Stiegler,

Mark Featherstone

Berardi, and the Digital Apocalypse 